\title{
Colour Feature Extraction Techniques of Fruits: A Survey
}

\author{
Ankur M Vyas \\ Computer Engineering Dept. \\ Sardar Vallabhbhai Patel \\ Institute of technology, \\ Vasad, Gujarat, India
}

\author{
Bjial Talati \\ HOD, Computer Engineering \\ Dept., Sardar Vallabhbhai Patel \\ Institute of technology, \\ Vasad, Gujarat, India
}

\author{
Sapan Naik \\ Asst. Prof. Computer Science \\ and Tech. Dept., \\ Uka Tarsadia University, \\ Bardoli, Gujarat, India
}

\begin{abstract}
There is a great significance of agriculture in India. Fruit grading can improve the revenue of fruits. In the automated fruit grading system the most important feature is its colour. So for any automated fruit grading system one should have the idea of colour space and segmentation needs to be performed. As colour feature extraction has a vital role in grading, here a review of various colour feature extraction techniques in detail is provided.
\end{abstract}

\section{General Terms}

Feature Extraction, Colour Feature.

\section{Keywords}

Colour spaces, Fruit grading, Image processing, Segmentation.

\section{INTRODUCTION}

Agriculture is a significant sector of Indian economy because it contributes 17 percent of the total Gross Domestic Product (GDP) of India and provides the employment to over 60 percent of population. India is ranked among the top three in terms of production of various agricultural commodities such as fruits, vegetables, food grains etc. and has emerged as the world's largest producer of Mango, Banana and Coconut [1] Agriculture is important in India because it has to support 17 percent of the world's population.

The global ranking of the country is 2 nd in terms of the productions of the fruits and vegetables next to China [2]. In the last two decades the highest increase in the terms of production was observed in cotton (>200 percent) which was followed by the fruits and vegetables ( 97 percent), condiments and spices (66 percent) and wheat (39 percent). The fruit mango occupies the first position in production accounting 37.2 percent of the total area in TE 2009-10 [3].

Due to advances in the computing technology image processing has the potential for application in agricultural processes where the guidance and grading is required [4]. Application of image processing as an analyzing tool in agriculture can improve the decision making for grading, fruit sorting etc. [5]. Table 1 summarizes few important application of image processing in agriculture.

In this paper Section 2 describes objective of our study. Section 3 explains various colour feature extraction techniques in detail. Finally section 4 draws the conclusion and future work.

Table 1.Application of image processing in agriculture

\begin{tabular}{|c|c|c|c|}
\hline \multicolumn{2}{|l|}{ Application } & \multirow{17}{*}{$\begin{array}{c}\text { Year } \\
1991\end{array}$} & \multirow{17}{*}{$\begin{array}{l}\text { References } \\
{[4]}\end{array}$} \\
\hline \multirow[t]{5}{*}{ Harvesting } & Oranges & & \\
\hline & Tomatoes & & \\
\hline & Mushrooms & & \\
\hline & Apples & & \\
\hline & Cucumbers & & \\
\hline \multirow[t]{7}{*}{ Grading } & Oranges & & \\
\hline & Potatoes & & \\
\hline & Apples & & \\
\hline & Carrots & & \\
\hline & Green Peppers & & \\
\hline & Tomatoes & & \\
\hline & Peaches & & \\
\hline \multirow[t]{3}{*}{ Detecting damage and diseases } & Corn & & \\
\hline & Rice & & \\
\hline & Soybeans & & \\
\hline \multicolumn{2}{|l|}{ Plant Growth Monitoring } & & \\
\hline \multicolumn{2}{|l|}{ Weed Leaf Image Segmentation } & 2001 & {$[6]$} \\
\hline \multicolumn{2}{|l|}{ Weed coverage determination } & 2003 & [7] \\
\hline \multicolumn{2}{|l|}{ Remote sensing } & 2003 & [8] \\
\hline \multicolumn{2}{|l|}{ Irrigation } & 1991 & [9] \\
\hline
\end{tabular}

\section{OBJECTIVE OF OUR STUDY}

Fruit grading on the basis of image processing is very useful because it improves fruit quality and reduce the manual work of grading. In fruit grading one can extract features such as fruit shape, colour and size in a nondestructive way. Then one can make some standard rules as grading criteria and then machine performs grading automatically [10]. Automated grading systems of fruits are having special priority because of the fact that there is ever-growing need of supply of high quality products within a short time [11]. Automatic grading 
systems can perform faster, resulting the grading in a short time, saving the time as well as manual labor. Many automatic grading systems are available for different fruits such as for the Apples [3]-[9], Oil Palm Fruits [19-20], Strawberries [21], Citrus [22] , Oranges [23], Mangoes [24], Lemons [11], Dates[31] etc.

Even though India produces fruits and vegetable in huge amounts then also it lacks in scientific grading systems. Much more research in field of agriculture is done in the countries like China, Japan, and USA as compared to India. In India most of the grading of fruits is based on size feature which is done manually. Developing automatic grading systems in India will benefit the agriculture to improve the fruit quality, saving the time as well as labor. So the objective is to develop the automated grading system of mangoes which would be economically beneficial to the agriculture. Because of the colour is such a vital feature in the grading, a review of the colour feature extraction techniques has been presented here.

\section{COLOUR FEATURE EXTRACTION TECHNIQUES}

Feature detection is a low-level image processing application. For an image, the feature is the "interest" part in image. In the pattern recognition literature the name feature is often used to denote a descriptor. Repeatability is the desirable property of a feature detector [25]. For the colour feature extraction the first step is segmentation. For the segmentation the choice of the colour space is also vital. Various popular colour spaces have been described in Table 2 which is referred from [26]. Details of it can also be found in [29].

Image segmentation can be done in various ways. Some of the image segmentation techniques in detail are shown in Table 3 referred from [26]. Image segmentation techniques in detail have been provided in [27-28].

Various techniques used in the colour feature extraction are explained below.

\subsection{Dominant Colour Method}

One of the techniques for the colour feature extraction used in the automated strawberry grading is the Dominant Colour Method. It represented the image of strawberry in $\mathrm{L}^{*} \mathrm{a} \mathrm{b}^{*}$ colour model. Generally, the human sight is more interested in main colour of the image means that colour which appears frequently in the image. So this Dominant Colour Method was used on $a^{*}$ channel to extract the colour feature from the image. It works as follows:

Step 1: It first calculates the histogram of the image on $a^{*}$ channel.

Step 2: Then it sets a window of width $\mathrm{L}$, and then from the most left of the histogram the gray value of the window is calculated. Then window is moved one pixel towards right and again the gray value is calculated. This procedure continues until window is moved towards the most right.

Step 3: Then the major colour window is found out i.e. the window having the largest frequency. And then by using the Eq. (1) the average colour value of the dominant window is found out.

$\overline{A S(L)}=\frac{\sum_{L} f\left(C_{i}\right)}{L}$

Where $\overline{A S(L)}$ is the average colour value, $\mathrm{L}$ is the width of histogram. And $\sum_{L} f\left(C_{i}\right)$ is the summation of the hue value $C_{i}$ of all histogram with $L$ width [21].

The $\mathrm{L}^{*} \mathrm{a} * \mathrm{~b} *$ model was also used in to detect the browning degree of mango [30]. The average $L * a * b *$ values were obtained from the image using the Histogram Window of Adobe Photoshop CS5. In the histogram window the parameters L, a, b were not standard colour values so they were converted as follows:

$$
\begin{aligned}
& L^{*}=\frac{L}{225} \times 100 \\
& a^{*}=\frac{240 a}{255}-120 \\
& b^{*}=\frac{240 b}{255}-120
\end{aligned}
$$

Table 2. Characteristics of colour spaces

\begin{tabular}{|l|l|l|}
\hline Colour Space & Advantages & Disadvantages \\
\hline$R G B$ & Convenient for display & $\begin{array}{l}\text { Due to its high correlation not good for } \\
\text { colour image processing }\end{array}$ \\
\hline$Y U V$ & $\begin{array}{l}\text { Less computation time and gets rid of } \\
\text { correlation of } R G B \text { to some extent }\end{array}$ & $\begin{array}{l}\text { Correlation still exists but not as high as } \\
R G B\end{array}$ \\
\hline HSI & $\begin{array}{l}\text { Based on human colour perception. } \\
\text { Hue is invariant of different types of } \\
\text { highlights, shadows and shading }\end{array}$ & $\begin{array}{l}\text { At low saturation it is numerically } \\
\text { unstable because of its nonlinear } \\
\text { transformation }\end{array}$ \\
\hline $\begin{array}{l}\text { CIE spaces } \\
\left(L * v^{*} \text { or } L * a * b *\right)\end{array}$ & $\begin{array}{l}\text { Colour and intensity information can be } \\
\text { controlled independently } \\
\text { Efficient in measuring small colour } \\
\text { difference }\end{array}$ & $\begin{array}{l}\text { Singularity problem as other nonlinear } \\
\text { transformations }\end{array}$ \\
\hline
\end{tabular}


Table 3.Monochrome image segmentation techniques

\begin{tabular}{|l|l|l|l|}
\hline Segmentation Method & Description & Advantages & Disadvantages \\
\hline Histogram thresholding & $\begin{array}{l}\text { Histogram is constructed having } \\
\text { peaks which correspond to a } \\
\text { region. }\end{array}$ & $\begin{array}{l}\text { Low computational complexity. } \\
\text { No prior information needed. }\end{array}$ & $\begin{array}{l}\text { Spatial details not considered, } \\
\text { cannot guarantee the } \\
\text { segmented regions to be } \\
\text { contiguous. }\end{array}$ \\
\hline $\begin{array}{l}\text { Region based } \\
\text { approaches }\end{array}$ & $\begin{array}{l}\text { Pixels are grouped in the } \\
\text { homogeneous regions, and region } \\
\text { merging, splitting or their } \\
\text { combination is used. }\end{array}$ & $\begin{array}{l}\text { Noise immune in edge detection } \\
\text { approach. }\end{array}$ & $\begin{array}{l}\text { High computational } \\
\text { complexity. } \\
\text { In region splitting segments } \\
\text { appear square due to splitting } \\
\text { scheme. }\end{array}$ \\
\hline $\begin{array}{l}\text { Edge detection } \\
\text { approaches }\end{array}$ & $\begin{array}{l}\text { Tries to locate the points having } \\
\text { changes in gray level. }\end{array}$ & $\begin{array}{l}\text { Works well for high contrast } \\
\text { images. }\end{array}$ & $\begin{array}{l}\text { Less immune to noise and } \\
\text { doesn't work well if the image } \\
\text { have too many edges. }\end{array}$ \\
\hline Fuzzy approaches & $\begin{array}{l}\text { Fuzzy operators, inference rules } \\
\text { and properties are applied. }\end{array}$ & $\begin{array}{l}\text { Approximate inference can be } \\
\text { performed by fuzzy IF-THEN } \\
\text { rules. }\end{array}$ & $\begin{array}{l}\text { Computation can be intensive } \\
\text { and determination of } \\
\text { membership function is not an } \\
\text { easy job. }\end{array}$ \\
\hline $\begin{array}{l}\text { Neural network } \\
\text { approaches }\end{array}$ & $\begin{array}{l}\text { Classification and clustering can } \\
\text { be performed. }\end{array}$ & $\begin{array}{l}\text { Less complicated and parallel } \\
\text { nature of neural network can be } \\
\text { used. }\end{array}$ & $\begin{array}{l}\text { Training time is long and } \\
\text { results can be affected by } \\
\text { initialization. }\end{array}$ \\
\hline
\end{tabular}

\subsection{Intensity Distribution Method}

This technique was used in the date fruit grading system. Dates were graded according to their flabbiness. The best quality was given to the flabbiest date. In order to estimate the flabbiness they used the colour intensity distribution in the image. They used the RGB colored image. The image is then converted in to gray level and then colour intensity was found from that.

The gray level can be obtained from the RGB image using below Eq. (5)

$G(x, y)=C(x, y) * R+C(x, y) * G+C(x, y) * B$

(5)

Where $(x, y) * R, C(x, y) * G, C(x, y) * B$ are the red, green and blue components of pixel $\mathrm{x}, \mathrm{y}$ in colour image C. $G(x, y)$ is the transformed gray level from RGB [31]. In the weeds identification through Support Vector Machines (SVM) the gray level of the image was obtained from the RGB images and the identification was carried out [32].

\subsection{Mean of colour in images}

This technique was used in mango grading system. They used RGB colour image. In order to determine the colour of the mango the mean of the colour array for red, green and blue was calculated using Eq. (6) as follows:

Mean image $=($ Red value $($ Find size image $)+$ Green value $($ Find size image $)+$ Blue value (Find size image) $) / 3$

And hence the mean of the colors were considered [24]. This technique was also used in the colour feature extraction in automated oil palm fruit grading system [19], oil palm bunch grading system using red-green-blue digital numbers [20], online fruit grading according to external quality using machine vision [18] to finds defects, grading of apples based on features extracted from defects [33], fish species classification [34], the fruit recognition system [35].The colors average were also taken in the in the automatic quality grading of fruits [36].

\subsection{Nine Colour Characteristic Data}

This method was used in apple colour grading. In that an image processor collected the composite video signal and that was processed to the 256 colour gradient of three primary colors in each pixel. Then apple image was extracted from it by removing the background. Then from the three primary colors the average colour gradients $(\bar{R}, \bar{G}, \bar{B})$, the variances $\left(V_{R}, V_{G}, V_{B}\right)$ and the chromatic coordinates (r, g, b) were calculated as follows. For e.g. Red:

$\bar{R}=R / n$

$V_{R}$

(8)

$r=\frac{R}{R+G+B}$

Where $\mathrm{n}$ is number of total pixels in the image data and $\mathrm{R}$ is equal to $\sum_{i=1}^{n} R_{i}$. So finally the nine colour characteristic data was obtained for the entire apple [15]. RGB and HSI both model were used in the apple colour grading based on organization feature parameters. They first found out the nine colour characteristic data, and then created the hue histogram. They divided the hue value into 8 equal intervals i.e. $c_{i}(i=$ $1,2, \ldots, 8)$. So new 8 colour features were obtained. So they obtained 17 colour feature parameters for an entire apple, they are $\bar{R}, \bar{G}, \bar{V}, V_{R}, V_{G}, V_{B}, r, g, b, c_{1}, c_{2}, c_{3}, c_{4}, c_{5}, c_{6}, c_{7}, c_{8}$ [14].

\subsection{HSI Colour Model Technique}

HSI colour model was used in the lemon sorting based on colour. The most popular colour model is the RGB colour model. Many algorithms of the fruit vision are based on the 
RGB colour model. Because of the RGB colour model is sensitive to the lighting or other conditions they preferred to use the HSI (Hue, Saturation and Intensity) colour model. Because of the Hue value is comparatively stable this model can be used efficiently. Here the colour is determined by the Hue value. The transformation used to convert RGB colour to HSI colour is as follows:

$\mathrm{H}=\cos ^{-1}\left\{\frac{(2 R-G-B) / 2}{(R-G)^{2}+(R-B)(G-B)^{\frac{1}{2}}}\right\}$

$\mathrm{S}=1-\frac{3}{(R+G+B)}[\min (\mathrm{R}, \mathrm{G}, \mathrm{B})]$

$\mathrm{I}=\frac{1}{3}(R+G+B)$

By closely examining the image histograms they found that accurate colour classification possible by only hue parameter [11]. This HSI model is also used in the apple sorting and grading [16]. They converted the image into binary and extracted colour features from the image. In the citrus sorting system five different colour spaces RGB, XYZ, HSI, La*b* and $\mathrm{Lu}^{*} \mathrm{v}^{*}$ were compared in order to classify defects they studied and stems. In order to obtain different classification functions in each colour space Linear Discriminant Analysis (LDA) was used, using the colour coordinates as independent variables. In that highest classification rate $(87 \%)$ was achieved with HSI [37].

In order to perform Starfruit maturity classification based on colour perception, the Hue component was extracted and classification was performed. After the transformation from RGB data to hue values, the resulting image was given to Discriminant Analysis (DA) and Multilayer Perceptron (MLP) to determine the fruit maturity or grade [38].

\subsection{YES Colour Model Technique}

In the adaptive texture and colour segmentation the YES model was used. After experimentally observing the effect of various colour spaces on segmentation, YES was selected. Luminance-Chrominance is known as the YES space, where "Y" represents Luminance and "E" and " $\mathrm{S}$ " represents chrominance components. This colour space was defined by a linear transformation if society of motion and picture and television engineers (SMTPE).

They get YES coordinates from RGB by following equation:

$\left[\begin{array}{l}Y \\ E \\ S\end{array}\right]=\left[\begin{array}{ccc}0.253 & 0.684 & 0.063 \\ 0.500 & -0.500 & 0.000 \\ 0.250 & 0.250 & -0.500\end{array}\right]$

$\left[\begin{array}{l}R \\ G \\ B\end{array}\right]$

(13)

The second important element was the choice of model for the object colour distribution. Although the colour histogram was simple and non-parametric method for colour modeling they require large datasets in order to work reliably and second drawback was difficulty in adapting the model over time. So they chose 2D Gaussian model for the colour distribution. It requires relatively little data and was also suitable for the adaptive colour segmentation.

Based on the chrominance components $\mathrm{E}$ and $\mathrm{S}$, a bivariate (2D) Gaussian distribution $\mathrm{N}\left(\mu_{c}, \sum_{c}^{2}\right)$ with mean $\mu_{c}$ and covariance $\sum_{c}$ is used to represent the distribution of object color.

The 2D Gaussian probability density function is given by:

$p\left(z_{c} \mid\right.$ object colour $)=$ $\frac{1}{2 \pi\left|\Sigma_{c}{ }^{1 / 2}\right|} \exp \left(-\frac{1}{2}\left[z_{c}-\mu_{c}\right]^{T} \sum_{c}^{-1}\left[z_{c}-\mu_{c}\right]\right)$

(14)

Where $\quad z_{c}=\left[\begin{array}{l}E \\ S\end{array}\right], \quad \mu_{c}=\left[\begin{array}{l}\mu_{E} \\ \mu_{S}\end{array}\right], \quad \sum_{c}=\left[\begin{array}{cc}\sigma_{E}^{2} & \sigma_{E S} \\ \sigma_{S E} & \sigma_{S}^{2}\end{array}\right] . \quad$ The distribution is simplified $p\left(z_{c} \mid\right.$ object colour $)$ Mahalanobis distance $\left(\left[z_{c}-\mu_{c}\right]^{T} \sum_{c}^{-1}\left[z_{c}-\mu_{c}\right]\right)$ by taking natural logarithm [39]. They used this technique to track moving objects; it can be used to extract colour feature different fruits.

\subsection{Different HSI and I1I2I3}

It was used to automatically identify the plant disease visual symptoms. Their purpose was to find the disease in plants visually with high accuracy. They used HSV because of its ability to deal with varying lighting conditions, and I1I2I3 because a previous study showed that this model worked well on the picture of plants.

Given that I exist in RGB colour space, they used the following transformations:

$$
\begin{aligned}
& m x_{(i, j)}=\max \left(I_{R(i, j)}, I_{G(i, j)}, I_{B(i, j)}\right) \\
& \min _{(i, j)}=\min \left(I_{R(i, j)}, I_{G(i, j)}, I_{B(i, j)}\right) \\
& H(i, j)= \\
& \left(\begin{array}{ll}
\frac{60 *\left(I_{G(i, j)}-I_{B(i, j)}\right)}{m x-\min } & I_{R(i, j)}>\max \left(I_{G(i, j)}, I_{B(i, j)}\right) \\
\frac{180 *\left(I_{B(i, j)-I_{R(i, j)}}\right)}{m x-\min } & I_{G(i, j)}>\max \left(I_{R(i, j)}, I_{B(i, j)}\right) \\
\frac{300 *\left(I_{R(i, j)}-I_{G(i, j)}\right)}{m x-\min } & I_{B(i, j)}>\max \left(I_{R(i, j)}, I_{G(i, j)}\right)
\end{array}\right) \\
& S(i, j)=\left[\frac{m x-m i n}{m x}\right] \\
& V(i, j)=[m x] \\
& (17)
\end{aligned}
$$

And I1I2I3 colour transformations are calculated by:

$$
\begin{aligned}
& I_{1}=\left(I_{R(i, j)}+I_{G(i, j)}+I_{B(i, j)}\right) / 3 \\
& \left.I_{2}=I_{R(i, j)}-I_{B(i, j)}\right) / 2 \\
& I_{3}=\left(\left(2 * I_{G(i, j)}\right) \sum I_{R(i, j)} \sum I_{B(i, j)}\right) / 4
\end{aligned}
$$

Where $0 \leq I_{R}, I_{G}, I_{B} \leq 255$.

The results of their test led to the selection of $\mathrm{I} 3$ and $\mathrm{H}$ colour transformations [40]. They used this technique to identify plant diseases; it can be used to extract colour feature different fruits.

\subsection{Simple RGB model}

The RGB model was used directly in assuring Coffee-Excelso Beans quality [41], automatic grading of Oil Fresh Fruit Bunches [42] and in [43]. The RGB and HSI both were also used in online detection of fruit defects [44].In the quality evaluation of Iyokan orange the images were captured and stored in 8 bit RGB image. R-G colour component ratio was found out from the image. The textural features like Angular Second Moment (ASM), Inverse Difference Moment (IDM) 
and contrast were calculated on green colour component image whose gray scale was reduced from 256 to 64 with the condition that distance was 16 pixels and angle was 0 . So in this way the co-occurrence matrix was created [23].

Global Colour Histogram $(\mathrm{GCH})$ was the technique used in the automatic fruit and vegetable classification of from images. All the images in the dataset which they used were stored in RGB colour space at 8 bits per channel. A GCH is the set of ordered values, one for each distinct colour, which represents the probability that a pixel belongs to that colour In order to avoid the scaling bias and to reduce the number of distinct colors, uniform quantization and normalization was used by them. They used 64-d GCH feature vector i.e. histogram with 64 bins (features). For the texture feature they used the 32-d Unser feature vector (histogram with 32 bins) which was calculated from the grayscale of the images [45].

\subsection{The Segmentation Method}

In the ripe tomato recognition and localization the YUV colour space was used. Firstly all the RGB values were converted in to YUV. They found out that as compared to R in RGB colour space, the V component in YUV colour space is more appropriate to describe the maturity in tomatoes. Also $\mathrm{V}$ component classifier separates ROI and from its background and noise. The threshold value for it can be given offline, or if there is no interaction the Otsu's threshold selection is used [46].

In the estimation of mango crop yield using image analysis the RGB and $\mathrm{YCbCr}$ components were used. The following method was used:

Step 1: Find Normalized Difference Index from $R$ \& $G$ values by Eq. (21) and pixels with NDI $>0$ were selected. In this step the pixels having red as more dominant part then green were selected.

$N D I=\frac{G-R}{G+R}$

Step 2: Then $3 \times 3$ variance filter was used to process the RGB image, which replaces each pixel by its neighborhood variance of the $\mathrm{R}, \mathrm{G}$, and $\mathrm{B}$ layers respectively. Then resulting image was converted to gray scale using $=(R+G+B) / 3$. Then thresholding using the condition $0<$ pixelvalue $\leq 90$ was performed.

This step removes the regions with large number of edges i.e. grass, foliage and also pixels with little variance i.e. sky

Step 3: Then the $\mathrm{Cr}$ layer was threshold using $\mathrm{Cr} \geq 150$. It removes brown grasses and tree trunk. Again $\mathrm{Cb}$ layer was threshold was performed using the condition of $\mathrm{Cb}>100$. Fruit and yellow leaf pixels in the $\mathrm{Cb}$ layer exhibited a very strong bipolar distribution, and the selection of 100 as a cut-off point was clearly within a wide gap between the two pixel types.

Step 4: By collating the previous steps the binary image was generated: pixel $_{\text {finalimage }}=$

pixel $_{N D I}$ and pixel variance $_{\text {and }}$ pixel $l_{C r}$ and pixel $l_{C b}$

Step 5: A count on the number of particles in the binary image was then performed. With the upper and lower limit of the pixels the particles were counted.

Thus, this step provided final count of the mangoes within the image [47]. Another method to predict the yield of Gala apples used the RGB model and threshold method for segmentation. The classification was quite simple. So finally the colour difference $R-B$ and $G-R$ were combined to segment apple fruits from background [17].

\subsection{Direct Colour Mapping Technique}

In rapid colour grading of fruit quality using the direct colour mapping the Direct Colour Mapping technique was used. They proposed the colour mapping methods that maps RGB values of the colors of interest into colour indices using a polynomial function.

After experiments, they choose to employ third order term $(\mathrm{R} \times \mathrm{G} \times \mathrm{B})$ and full rank second order polynomial $\left(R^{2}, G^{2}, B^{2}, R \times G, R \times B, G \times B, R, G, B\right.$ \& constant value) to convert 3-D colors to $1-\mathrm{D}$ indices. They also found out using higher than three-ordered terms increases the complexity but not the accuracy. The formula for the conversion is given by Eq. (22) as follows:

Colour Index $=c_{1} \cdot R \cdot G \cdot B+\sum_{i=2}^{7} c_{i} \cdot R^{l} \cdot G^{m} \cdot B^{n}$

$+\sum_{i=8}^{10} c_{i} \cdot R^{o} \cdot G^{p} \cdot B^{q}+c_{11}$

(22)

Where $1, \mathrm{~m}, \mathrm{n}, \mathrm{o}, \mathrm{p}$, and $\mathrm{q}$ are all greater than or equal to 0 and $l+m+n=2$ to form the second order terms and $o+p+$ $q=1$ to form the all first order terms. One thing should be noted that $c_{1}, c_{2}, \ldots c_{11}$ must be specified in order to use this formula. Colors differing slightly from the predefined value will be mapped to the closest value. Here one set of preselected colors of interest must be given. At least 11 samples colors based on application colour range are needed to solve 11 coefficients. So Eq. (22) can be written in matrix form as Eq. (23).In Eq. (23) $R_{i}, G_{i}$, and $B_{i}$ for $i=1,2,3, \ldots, n$ are the RGB values of the of the preselected colour samples and $v_{1}, v_{2}, \ldots, v_{n}$ are the desired linear indices.

The value of $\mathrm{n}$ depends on how many sample colors are used. The coefficients can be calculated by least-squared error method. They selected Singular Value Decomposition (SVD) because a singleton solution may not exist due to imperfect selection of sample colors. It also allows us to use more than 11 sample colors [48].

Finally the Table 4 summarizes the colour feature extraction techniques studied along with the advantages and disadvantages of these techniques.

$\left[\begin{array}{ccccccccccc}R_{1} G_{1} B_{1} & R_{1}^{2} & G_{1}^{2} & B_{1}^{2} & R_{1} G_{1} & R_{1} B_{1} & G_{1} B_{1} & R_{1} & G_{1} & B_{1} & 1 \\ R_{2} G_{2} B_{2} & R_{2}^{2} & G_{2}^{2} & B_{2}^{2} & R_{2} G_{2} & R_{2} B_{2} & G_{2} B_{2} & R_{2} & G_{2} & B_{2} & 1 \\ \vdots & \vdots & \vdots & \vdots & \vdots & \vdots & \vdots & \vdots & \vdots & \vdots & \vdots \\ R_{n} G_{n} B_{n} & R_{n}^{2} & G_{n}^{2} & B_{n}^{2} & R_{n} G_{n} & R_{n} B_{n} & G_{n} B_{n} & R_{n} & G_{n} & B_{n} & 1\end{array}\right]\left[\begin{array}{c}c_{1} \\ c_{2} \\ \vdots \\ c_{n}\end{array}\right]=\left[\begin{array}{c}v_{1} \\ v_{2} \\ \vdots \\ v_{n}\end{array}\right]$ 
Table 4. Colour feature extraction techniques

\begin{tabular}{|c|c|c|c|c|c|}
\hline $\begin{array}{l}\text { Colour Feature } \\
\text { Extraction } \\
\text { Technique } \\
\end{array}$ & Fruit & Accuracy & Advantages & Disadvantages & Reference \\
\hline $\begin{array}{l}\text { Dominant Colour } \\
\text { Method }\end{array}$ & Strawberry & $88.8 \%$ & $\begin{array}{l}\text { Close to human } \\
\text { vision feeling. } \\
\text { Grading precision } \\
\text { increased. }\end{array}$ & $\begin{array}{l}\text { Computationally } \\
\text { complex. }\end{array}$ & Xu Liming, 2010 [21] \\
\hline $\begin{array}{l}\text { Intensity } \\
\text { Distribution } \\
\text { Method }\end{array}$ & Date & $80 \%$ & $\begin{array}{l}\text { Easy to implement } \\
\text { only conversion to } \\
\text { grayscale required. }\end{array}$ & $\begin{array}{l}\text { High contrast images } \\
\text { required. }\end{array}$ & Yousef Al Ohali, 2011 [31] \\
\hline \multirow{8}{*}{$\begin{array}{l}\text { Mean of colour in } \\
\text { images }\end{array}$} & Mango & More than $80 \%$ & \multirow{8}{*}{$\begin{array}{l}\text { Requires less } \\
\text { computation. } \\
\text { Easy to implement. }\end{array}$} & \multirow{8}{*}{$\begin{array}{l}\text { Mean of colour is } \\
\text { taken as not accurate } \\
\text { as other methods. }\end{array}$} & $\begin{array}{l}\text { Tajul Rosli Bin Razak, } 2012 \\
\text { [24] }\end{array}$ \\
\hline & Oil Palm Fruit & $86.67 \%$ & & & Z. May, 2011 [19] \\
\hline & $\begin{array}{l}\text { Palm Oil Fresh } \\
\text { Fruit Bunches }\end{array}$ & $73.3 \%$ & & & $\begin{array}{l}\text { Meftah Salem M. Alfatni, } \\
2008 \text { [20] }\end{array}$ \\
\hline & \multirow{4}{*}{ Apples } & $\begin{array}{l}78 \% \text { for Golden } \\
\text { Delicious }\end{array}$ & & & V Leemans 2002 [18] \\
\hline & & $\begin{array}{l}72 \% \text { for } \\
\text { Jonagold }\end{array}$ & & & 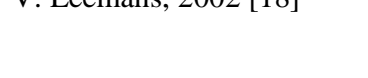 \\
\hline & & $\begin{array}{l}73 \% \text { for } \\
\text { Jonagold }\end{array}$ & & & V. Leemans , 2004 [33] \\
\hline & & $\begin{array}{l}86 \% \text { in blemish } \\
\text { detection }\end{array}$ & & & J Blasco,2003 [36] \\
\hline & $\begin{array}{l}\text { Different Fruits } \\
\text { classification }\end{array}$ & $90 \%$ & & & Woo Chaw Seng, 2009 [35] \\
\hline \multirow{2}{*}{$\begin{array}{l}\text { Nine Colour } \\
\text { Characteristic } \\
\text { Data }\end{array}$} & Apples & - & \multirow{2}{*}{$\begin{array}{l}\text { More accurate cause } \\
\text { many parameters } \\
\text { were considered. }\end{array}$} & \multirow{2}{*}{$\begin{array}{l}\text { Requires more } \\
\text { computation. }\end{array}$} & Kazuhiro Nakano,1997 [15] \\
\hline & & - & & & Zou Xiaobo,2007 [14] \\
\hline \multirow{5}{*}{$\begin{array}{l}\text { HSI Colour Model } \\
\text { Technique }\end{array}$} & Lemon & $94.04 \%$ & \multirow{5}{*}{$\begin{array}{l}\text { Hue value is } \\
\text { comparatively stable } \\
\text { and less sensitive to } \\
\text { lightning conditions. }\end{array}$} & \multirow{5}{*}{$\begin{array}{l}\text { Colour } \\
\text { transformation to } \\
\text { HSI is required. }\end{array}$} & $\begin{array}{l}\text { M. Khojastehnazhand, } 2010 \\
\text { [11] }\end{array}$ \\
\hline & Apple & - & & & P. Sudhakara Rao,2002 [16] \\
\hline & Citrus & $87 \%$ & & & J. Blasco, 2007 [37] \\
\hline & \multirow{2}{*}{ Starfruit } & LDA: $95.3 \%$ & & & \multirow{2}{*}{ M.Z. Abdullah, 2006 [38] } \\
\hline & & MLP: $90.5 \%$ & & & \\
\hline \multirow{2}{*}{$\begin{array}{l}\text { Simple RGB } \\
\text { model }\end{array}$} & $\begin{array}{l}\text { Palm Oil Fresh } \\
\text { Fruit Bunches }\end{array}$ & $86.67 \%$ & \multirow{2}{*}{$\begin{array}{l}\text { Less complex. } \\
\text { Easy to implement. }\end{array}$} & \multirow{2}{*}{$\begin{array}{l}\text { Sensitive to lightning } \\
\text { and other conditions. }\end{array}$} & $\begin{array}{l}\text { Meftah Salem M. Alfatni, } \\
2008 \text { [20] }\end{array}$ \\
\hline & Apple & $89 \%$ & & & Xu Qiabao, 2009 [44] \\
\hline \multirow{2}{*}{$\begin{array}{l}\text { The Segmentation } \\
\text { Method }\end{array}$} & Tomato & - & \multirow{2}{*}{$\begin{array}{l}\text { Simple and fast } \\
\text { results }\end{array}$} & \multirow{2}{*}{$\begin{array}{l}\text { Colour } \\
\text { transformation } \\
\text { required. }\end{array}$} & Xuming Chen,2013[46] \\
\hline & Mango & - & & & A.B. Payne , 2013 [47] \\
\hline \multirow{2}{*}{$\begin{array}{l}\text { Direct Colour } \\
\text { Mapping } \\
\text { Technique }\end{array}$} & Tomato & $95 \%$ & \multirow{2}{*}{$\begin{array}{l}\text { Simple. } \\
\text { Effective. } \\
\text { Accurate. }\end{array}$} & \multirow{2}{*}{$\begin{array}{l}\text { Transformation from } \\
3 \mathrm{~d} \text { to } 1 \mathrm{~d} \text { colour space } \\
\text { required. }\end{array}$} & \multirow{2}{*}{ Dah-Jye Lee, 2010 [48] } \\
\hline & Dates & More than $87 \%$ & & & \\
\hline
\end{tabular}




\section{CONCLUSION AND FUTURE DIRECTION}

As colour is the vital feature in the grading of the fruits so in this paper some of the techniques for the colour feature extraction was reviewed. India lacks of the scientific grading systems for the fruits. Though having such a high rank in production of fruits and vegetables, they suffer from the quality issues. If automatic grading systems are available then it would save the time as well as the manual labor. And most important their quality can be judged.

Because of India is void of such automatic grading systems, development of such grading systems which could economically help the agriculture can be planed. Different colour feature extraction techniques can be used for different kinds of fruits and vegetables. Some advantages and disadvantages are listed in Table 4. Different new algorithms can be created for the grading task. Advantages of different techniques can be combined to improve the accuracy and efficiency of grading.

\section{REFERENCES}

[1] Chaudhary Charan Singh National Institute of Agriculture Marketing Website. [Online]. www.ccsniam.gov.in/research/KCG\%20Final\%20report. pdf

[2] MM Pandey, "INDIAN AGRICULTURE - AN INTRODUCTION," Asian and Pacific Centre for Agricultural Engineering and Machinery (APCAEM), Thailand, Country Report: INDIA 2009.

[3] Vijay Paul Sharma and Dinesh Jain. (2011, July) [Online].

www.iimahd.ernet.in:8181/assets/upload/faculty/678631 189High\%20Value\%20Agri.\%20Working\%20Paper.pdf

[4] R.D. Tillett, "Image analysis for agricultural processes: a review of potential opportunities," Journal of Agricultural Engineering Research, vol. 50, pp. 247-258, September-December 1991.

[5] Anup Vibhute and S K Bodhe, "Applications of Image Processing in Agriculture: A Survey," International Journal of Computer Applications, vol. 52, no. 2, pp. 3440, August 2012

[6] A.-G. Manh, G. Rabatel, L. Assemat, and M.-J. Aldon, "AE-Automation and Emerging Technologies: Weed Leaf Image Segmentation by Deformable Templates," Journal of Agricultural Engineering Research, vol. 80, no. 2, pp. 139-146, October 2001.

[7] Chun-Chieh Yang, Shiv O. Prasher, Jacques-André Landry, and Hosahalli S. Ramaswamy, "Development of an Image Processing System and a Fuzzy Algorithm for Site-Specific Herbicide Applications," Precision Agriculture, vol. 4, no. 1, pp. 5-18, March 2003.

[8] Santhosh K Seelan, Soizik Laguette, Grant M Casady, and George A Seielstad, "Remote sensing applications for precision agriculture: A learning community approach," Remote Sensing of Environment, vol. 88, no. 1-2, pp. 157-169, November 2003.

[9] M. S. Moran, "Irrigation management in Arizona using satellites and airplanes," Irrigation Science, vol. 15, no. 1, pp. 35-44, September 1991

[10] Hongshe Dang, Jinguo Song, and Qin Guo, "A Fruit Size Detecting and Grading System Based on Image
Processing," Intelligent Human-Machine Systems and Cybernetics (IHMSC), 2010 2nd International Conference on, vol. 2, pp. 83-86, August 2010.

[11] M. Khojastehnazhand, M. Omid, and A. Tabatabaeefar, "Development of a lemon sorting system based on colour and size," African Journal of Plant Science, vol. 4(4), pp. 122-127, April 2010

[12] Ashutosh Kumar Bhatt, Durgesh Pant, and Richa Singh, "An analysis of the performance of Artificial Neural Network technique for apple classification," $A I$ \& SOCIETY, May 2012.

[13] Akira Mizushima and Renfu Lu, "An image segmentation method for apple sorting and grading using support vector machine and Otsu's method," Computers and Electronics in Agriculture, vol. 94, pp. 29-37, June 2013.

[14] Zou Xiaobo, Zhao Jiewen and Li Yanxiao, "Apple colour grading based on organization feature parameters," Pattern Recognition Letters, vol. 28, pp. 2046-2053, June 2007.

[15] Kazuhiro Nakano, "Application of neural networks to the colour grading of apples," Computers and Electronics in Agriculture, vol. 18, no. 2-3, pp. 105-116, August 1997.

[16] P. Sudhakara Rao and S. Renganathan, "New Approaches for Size Determination of Apple Fruits for Automatic Sorting and Grading," IRANIAN JOURNAL OF ELECTRICAL AND COMPUTER ENGINEERING vol. 1, no. 2, March 2002.

[17] Rong Zhou, Lutz Damerow, Yurui Sun, and Michael M Blanke, "Using colour features of cv. 'Gala' apple fruits in an orchard in image processing to predict yield," Precision Agriculure, vol. 13, no. 5, pp. 568-580, October 2012

[18] V. Leemans, H. Magein, and M.-F. Destain, "AEAutomation and Emerging Technologies: On-line Fruit Grading according to their External Quality using Machine Vision," Biosystems Engineering, vol. 83, no. 4, pp. 397-404, December 2002.

[19] Z. May and M. H. Amaran, "Automated Oil Palm Fruit Grading System using Artificial Intelligence," International Journal of Video \& Image Processing and Network Security, vol. 11, no. 03, June 2011.

[20] Meftah Salem M. Alfatni , Abdul Rashid Mohamed Shariff , Helmi Zulhaidi Mohd Shafri, Osama M. Ben Saaed, and Omar M. Eshanta , "Oil Palm Fruit Bunch Grading System Using Red, Green and Blue Digital Number," Journal of Applied Sciences, vol. 8, no. 8, pp. 1444-1452, 2008.

[21] Xu Liming and Zhao Yanchao, "Automated strawberry grading system based on image processing," Computers and Electronics in Agriculture, vol. 71, no. Supplement 1, pp. S32-S39, April 2010.

[22] U. Ahmad, M. Suhil, R. Tjahjohutomo, and H.K. Purwadaria, "Development of Citrus Grading System Using Image Processing".

[23] Naoshi Kondo, Usman Ahmad, Mitsuji Monta, and Haruhiko Murase, "Machine vision based quality evaluation of Iyokan orange fruit using neural networks," 
Computers and Electronics in Agriculture, vol. 29, no. 12, pp. 135-147, October 2000.

[24] Tajul Rosli Bin Razak, Mahmod Bin Othman(DR), Mohd Nazari Bin Abu Bakar(DR), Khairul Adilah BT Ahmad, and AB.Razak Bin Mansor, "Mango Grading By Using Fuzzy Image Analysis," in In proceedings of International Conference on Agricultural, Environment and Biological Sciences, Phuket, 2012.

[25] K. Padmavathi, "Investigation and monitoring for leaves disease detection and evaluation using image processing," International Research Journal of Engineering Science, Technology and Innovation, vol. 1, no. 3, pp. 66-70, June 2012.

[26] Cheng, Heng-Da, X. H. Jiang, Ying Sun, and Jingli Wang. "Colour image segmentation: advances and prospects." Pattern recognition 34, no. 12 (2001): 22592281.

[27] Satish Kachhadiya, Nitin Gondaliya, and Amit Chaudhari, "A comprehensive study of image segmentation," International Journal of Computer Science and Information Technology \& Security, vol. 2, no. 6, pp. 1120-1125, December 2012.

[28] Gonzalez, Rafael C., Richard E. Woods, and S. L. Eddins. "Image segmentation." Digital Image Processing (2002): 577-581

[29] Gonzalez, Rafael C., Richard E. Woods, and S. L. Eddins. "Colour image processing." Digital Image Processing (2002): 289-301.

[30] Hong Zheng and Hongfei Lu, "A least-squares support vector machine (LS-SVM) based on fractal analysis and CIELab parameters for the detection of browning degree on mango (Mangifera indica L.)," Computers and Electronics in Agriculture, vol. 83, pp. 47-51, January 2012.

[31] Yousef Al Ohali, "Computer vision based date fruit grading system: Design and implementation," Journal of King Saud University - Computer and Information Sciences, vol. 23, no. 1, pp. 29-39, January 2011

[32] Alberto Tellaeche, Gonzalo Pajares, Xavier P. BurgosArtizzu, and Angela Ribeiro, "A computer vision approach for weeds identification through Support Vector Machines," Applied Soft Computing, vol. 11, no. 1, pp. 908-915, January 2011.

[33] V. Leemans and M.-F. Destain, "A real-time grading method of apples based on features extracted from defects," Journal of Food Engineering, vol. 61, no. 1, pp. 83-89, January 2004.

[34] Jing Hu et al., "Fish species classification by color, texture and multi-class support vector machine using computer vision," Computers and Electronics in Agriculture, vol. 88, pp. 133-140, October 2012.

[35] Woo Chaw Seng and Seyed Hadi Mirisaee, "A New Method for Fruits Recognition System," Electrical Engineering and Informatics, vol. 01, pp. 130-134, August 2009.

[36] J Blasco, N Aleixos, and E Moltó, "Machine Vision System for Automatic Quality Grading of Fruit," Biosystems Engineering, vol. 85, no. 4, pp. 415-423, August 2003.
[37] J. Blasco, N. Aleixos, J. Gómez, and E. Moltó, "Citrus sorting by identification of the most common defects using multispectral computer vision," Journal of Food Engineering, vol. 83, no. 3, pp. 384-393, December 2007.

[38] M.Z. Abdullah, J. Mohamad-Saleh, A.S. Fathinul-Syahir, and B.M.N. Mohd-Azemi, "Discrimination and classification of fresh-cut starfruits (Averrhoa carambola L.) Using automated machine vision system," Journal of Food Engineering, vol. 76, no. 4, pp. 506-523, October 2006.

[39] Ercan Ozyildiz, Nils Krahnstover, and Rajeev Sharma, "Adaptive texture and colour segmentation for tracking moving objects," Pattern Recognition, vol. 35, pp. 2013 2029,2002

[40] A. Camargoa and J.S. Smith, "An image-processing based algorithm to automatically identify plant disease visual symptoms," BIOSYSTEMS ENGINEERING, vol. 102, no. 1, pp. 9-21, January 2009.

[41] Eduardo Carrillo and Alexander Aristizábal Peñaloza, "Artificial vision to assure coffee-Excelso beans quality," in EATIS, Czech Republic, 2009, p. 35.

[42] Nursuriati Jamil, Azlinah Mohamed, and Syazwani Abdullah, "Automated Grading of Palm Oil Fresh Fruit Bunches (FFB) using Neuro-Fuzzy Technique," 2009 International Conference of Soft Computing and Pattern Recognition, pp. 245-249, 2009.

[43] B.G Prasad, K.K Biswas, and S.K Gupta, "Region-based image retrieval using integrated color, shape, and location index," Computer Vision and Image Understanding, vol. 94, no. 1-3, pp. 192-233, April-June 2004.

[44] Xu Qiabao, Zou Xiaobo, and Zhao Jiewen, "On-Line Detection of Defects on Fruit by Machinevision Systems Based on Three-Color-Cameras Systems," Computer and Computing Technologies in Agriculture II, vol. 3, pp. 2231-2238, 2009.

[45] Anderson Rocha, Daniel C. Hauagge, Jacques Wainer, and Siome Goldenstein, "Automatic fruit and vegetable classification from images," Computers and Electronics in Agriculture, vol. 70, no. 1, pp. 96-104, January 2010.

[46] Xuming Chen and Simon X. Yang, "A practical solution for ripe tomato recognition and localisation," Journal of Real-Time Image Processing, vol. 8, no. 1, pp. 35-51, January 2013.

[47] A.B. Payne, K.B. Walsh, P.P. Subedi, and D. Jarvis, "Estimation of mango crop yield using image analysis Segmentation method," Computers and Electronics in Agriculture, vol. 91, pp. 57-64, February 2013.

[48] Dah-Jye Lee, James K. Archibald, and Guangming Xiong, "Rapid Colour Grading for Fruit Quality Evaluation Using Direct Colour Mapping," IEEE TRANSACTIONS ON AUTOMATION SCIENCE AND ENGINEERING, vol. 8, no. 2, pp. 292-302, November 2010. 